\title{
ОЦЕНКА ЭФФЕКТИВНОСТИ СОЧЕТАННОГО ПРИМЕНЕНИЯ ПРЕПАРАТОВ МАГНИЯ И МИКРОНИЗИРОВАННОГО ПРОГЕСТЕРОНА ПРИ УГРОЗЕ НЕВЫНАШИВАНИЯ БЕРЕМЕННОСТИ
}

\author{
Е.А. Дубровина ${ }^{1 *}$, Г.В. Дубровина ${ }^{2}$ С.В. Нотова ${ }^{3}$ \\ ${ }^{1}$ Оренбургский государственный медицинский университет, г. Оренбург, Россия \\ ${ }^{2}$ Оренбургский клинический перинатальный центр, г. Оренбург, Россия \\ ${ }^{3}$ Оренбургский государственный университет, г. Оренбург, Россия \\ *e-mail: liza5567@yandex.ru
}

РЕЗЮМЕ. Результаты многочисленных исследований указывают на то, что во время беременности возрастает потребность в магнии. Недостаток данного элемента на ранних сроках беременности является фактором риска возникновения угрозы прерывания беременности, в связи с этим была поставлена цель исследования. В ходе обследования женщин в возрасте от 25 до 35 лет со сроком гестации до 12 недель и с угрозой невынашивания беременности выявлено, что сочетанное применение препарата магния (940 мг/сутки) и микронизированного прогестерона (400 мг/сутки) снижает побочные эффекты прогестерона и способствует повышению показателей психофизиологической адаптации. Установлено, что в группе женщин, получавших комбинированное лечение, были достоверно выше: уровень магния в крови (0,79 ммоль/л); показатели адаптации сердечно-сосудистой системы по индексу Баевского и показатели теста САН.

КЛЮЧЕВЫЕ СЛОВА: магний, невынашивание беременности, микронизированный прогестерон, индекс Баевского, функциональное состояние.

\section{EVALUATION OF BLOOD MAGNESIUM LEVEL AND FUNCTIONAL STATE OF WOMEN AT THE THREAT OF PERMANENT PREGNANCY}

\author{
E.A. Dubrovina ${ }^{1 *}$, G.V. Dubrovina ${ }^{2}$, S.V. Notova ${ }^{3}$ \\ ${ }^{1}$ Orenburg State Medical University, Orenburg, Russia \\ ${ }^{2}$ Orenburg Clinical Perinatal Center, Orenburg, Russia \\ ${ }^{3}$ Orenburg State University, Orenburg, Russia \\ *e-mail: liza5567@yandex.ru
}

ABSTRACT. During pregnancy, a woman is more susceptible to magnesium deficiency, due to an increase in the need for this trace element. During the examination of women aged 25 to 35 years with a gestation period of up to 12 weeks and with the threat of miscarriage, it was revealed that the combined use of magnesium (940 mg/day) and micronized progesterone $(400 \mathrm{mg} /$ day) reduces the side effects of progesterone and contributes to an increase in the indicators of psychophysiological adaptation. It was found that in the group of women who received combined treatment, the following were significantly higher: the level of magnesium in the blood $(0.79 \mathrm{mmol} / \mathrm{l})$; indicators of adaptation of the cardiovascular system according to the Baevsky R.M. index and the indicators of the "SAN" test.

KEYWORDS: magnesium, interruption of pregnancy, micronized progesterone, index Baevsky, functional state.

\section{ВВЕДЕНИЕ}

Магний является универсальным регулятором физиологических и биохимических процессов организма. Наиболее зависимыми от магния тканями являются: плацента, матка, мозг, миокард (Дикке, 2016). К одной из причин развития магниевого дефицита относится беременность. Важным фактором, определяющим нормальное развитие эмбриона и протекания беременности, считается достаточный уровень прогестерона и магния (Радыш, Скальный, 2015; Лисицына, Хилькевич, 2018).

Цель исследования - оценить эффективность сочетанного применения препаратов магния и микронизированного прогестерона при угрозе невынашивания беременности.

\section{МАТЕРИАЛЫ И МЕТОДЫ}

На базе ГБУЗ «Оренбургский клинический перинатальный центр» было проведено обследование 30 беременных женщин со сроком гестации до 12 недель, в возрасте от 25 до 35 лет, которые проживают на 
территории Оренбургской области; от всех женщин были получены информированные согласия. Критериями исключения являлось наличие острых и обострение хронических заболеваний. Исследуемых разделили на две группы: I группа - микронизированный прогестерон (200 мг 2 раз в сутки) и препарат $\mathrm{Mg}$ (470 мг 2 раза в сутки), II группа - только прогестерон. Курс приема препаратов составил 4 недели.

Определение уровня магния в крови натощак проводилось в аккредитованной лаборатории на биохимическом анализаторе Сапфир-400 (нормальные показатели уровня магния составляют 0,70-0,98 ммоль/л). Функциональное состояние беременных оценивалось с помощью индекса Баевского и тестаСАН. Статистическую обработку данных проводили с помощью программного пакета Statistica 10.0 .

\section{РЕЗУЛЬТАТЫ И ОБСУЖДЕНИЕ}

У беременных I группы показатели уровня магния в крови $(0,79(0,74-0,85))$ достоверно выше, чем во II группе $(0,65(0,61-0,69)(p<0,05)$. У женщин I группы наблюдалась удовлетворительная адаптация системы кровообращения $(1,34(1,22-1,47))$. Во II группе Ме индекса Баевского находилась на границе удовлетворительной и напряженной адаптации $(2,6(1,29-2,73))$, что говорит о наличии статистически значимого различия между женщинами I и II группы $(p<0,05)$. При оценке результатов опросника САН было вы-яснено, чтоу женщин II группы показатели активности (А) и настроения (Н) достоверно ниже (А - 28,0 (25,2-29,8), H - 33,5 (30,8-47,8)), чем у беременных I группы (A - 44,0 (39,0-50,3), H - 61,5 (58,5$66,8))$.

\section{ВЫВОДЫ}

Полученные результаты подтверждают эффективность комплексного применения микронизированного прогестерона и препарата магния, так как одновременное использование снижает побочные эффекты микронизированного прогестерона и способствует лучшей адаптации сердечно-сосудистой системы.

\section{Список литературы / References}

1. Дикке Г.Б. Роль магния при физиологической беременности: контраверсии и доказательства. Медицинский совет. 2016 ; 19 : 96-102.

2. Лисицына О.И., Хилькевич Е.Г. Применение препаратов магния во время беременности. Медицинский совет. $2018 ; 7: 50-53$.

3. Радым И.В., Скальный А.В. Введение в медицинскую элементологию: учебное пособие. М.: Российский ун-т дружбы народов, 2015:198 c. 